\title{
Origins of Inflammopharmacology. Twenty-five years on
}

\author{
K. D. Rainsford ${ }^{1}$
}

Published online: 8 November 2016

(C) Springer International Publishing 2016

It was at the suggestion of Professor Michael Whitehouse (see previous Editorial) that I should give a brief account of how the journal was started, the raison d'etre for its existence, and now 25 years since it was first published what the future holds for this multi-disciplinary journal.

The beginnings of inflammopharmacology (IPH) started when Dr. Peter Clarke, a commissioning editor from MTP (Lancaster, UK, later taken over by Kluwer) came to my laboratory in Cambridge in 1988 and asked if I would be interested in establishing a new journal for publishing papers in the general area of the pharmacology of inflammation. I was about to take up a new post as a joint professor in Biomedical Sciences (Pharmacology) and Pathology at McMaster University Faculty of Health Sciences in Hamilton, Ontario, Canada. The thought of trying to establish a new journal while at the same time setting up new research programmes and collaborations, teaching medical and biomedical subjects, and promoting the development of a Pharmacology of Rheumatic Diseases group presented a daunting, if not formidable prospect. However, after discussing the ideas and working out what could be done with colleagues it seemed to be a worthwhile project. My colleagues at McMaster University were particularly enthusiastic, among them Professors Watson Buchanan, Walter Kean, Richard Hunt and Alan McComas.

By 1991, we had published the first issues of volume 1 (Table 1) and interest in the journal progressively

K. D. Rainsford

k.d.rainsford@shu.ac.uk

1 Emeritus Professor of Biomedical Sciences, Editor-in-Chief, Inflammopharmacology, BMRC, Sheffield Hallam University, Howard Street, Sheffield S1 1WB, UK developed. The first publisher, Kluwer Academic (Dordrecht, The Netherlands) produced six volumes up until 1998. Subsequently, this publisher handed over the publication to another Dutch publisher, VSP (http:// www.vsp.com; Utrecht) who continued later as part of Koninklinje Brill NV until volume 13 was published in 2005 (Table 2). Considerable interest had developed at this stage thanks to the support of a widening Editorial Board, special issues devoted to topical subjects, and publication of peer-reviewed papers selected from conferences on the "Side Effects of Anti-inflammatory Drugs (SEADs) and later the "Inflammopharmacology" series (Table 2).

A matter of concern then to me was that the previous publishers had not been able to get a journal cited in Index Medicus (PubMed) or the Institute for Scientific Information (ISI) Web of Science. I was not appraised of the situation about citation on these indexes. I had discussed the issue about how the future development of the journal could be progressed and the citation issue with a considerable number of scientists, physicians in the field of gastroenterology, rheumatology and internal medicine, as well as with academic publishers. I had decided that we needed to seek a publisher who would have the experience of publishing research in the field of inflammation and who had the facilities to make the wider scientific and medical world aware of the journal, to promote its interests and to seek citation and impact factor ratings. By good luck, I was participating in a conference in Rome in 2005 at which my wife and I were having lunch in which Dr. Detlef Klüber from Birkhäuser Verlag, Basel, was at our table when discussion took place about journal publications. I had known Dr. Klüber from being previously involved with him in book publications. My wife suggested to me that 
Table 1 Titles of papers in the first volume of Inflammopharmacology

Inflammopharmacology

Vol. 1 no. 1; 1991 Contents

Editorial statement

Molecular pathology of drug-disease interactions in chronic autoimmune

Inflammatory diseases

A.L. Parke, D.F.V. Lewis and D.V. Parke

Relationship between enantiomer levels of flurbiprofen and clinical response

In rheumatoid arthritis

N. Bellamy, S. Cox and J. Campbell

Solcoseryl prevents inflammatory and hypoxic but not liver injury in rodents

T. Hartung, M. Leist, G. Tiegs, W. Baschong and A. Wendel

Conditional pharmacology: expression of anti-inflammatory activity may require

Pre-existent inflammatory mediators/hormones

M.W. Whitehouse and B. Vernon-Roberts

Pharmacokinetic interactions and adverse drug experiences in rheumatoid

Arthritis

D.E. Furst

Inflammation Research Association Meeting Report

K.D. Rainsford

Instructions for Authors and Editorial Policy

Vol. 1 no. 2; 1991 Contents

Editorial commentary

Editorial: the antirheumatic gold complexes: considerations of chemical form

In studies on their mechanism of action

G.G. Graham, G.D. Champion and Z.B. Ziegler

Gold complex research in medical science. Difficulties with experimental design

W.F. Kean, C.J.L. Lock and H. Howard-Lock

NSAIDs: clinical efficacy and toxicity

W.W. Buchanan and N. Bellamy

Interaction between flurbiprofen and $\mathrm{H}_{2}$-antagonists in rheumatoid arthritis

J.H. Kreeft, N. Bellamy, D. Freeman and J. Campbell

Disease-drug interaction: significance or insignificance of the $\mathrm{ED}_{50}$ value for anti-inflammatory agents

M.W. Whitehouse

Effect of benzydamine, a topically administered NSAID, on in vitro prostanoid

synthesis by human and rat gastric mucosa and rat kidney, aorta and urinary bladder: lack of effect on cyclooxygenase but potent inhibition of receptor-linked prostanoid synthesis

J.Y. Jeremy, R.M. Kirk and D.P. Mikhailidis

Discriminating effects of a nucleotide-rich yeast extract, Probioticum ${ }^{\mathrm{R}}$, as an immunomodulator contrasted

with actions in chronic immuno-inflammatory disease (adjuvant-induced arthritis) in rodents

G. Burmeister and K.D. Rainsford

Instructions to Authors and Editorial Policy

Vol. 1 no. 3; 1992 Contents

Editorial commentary

A statistical matching of patients with dermatomyositis and polymyositis:

A preliminary feasibility study

K.E. Tymms, E.M. Beller, L. Schrieber, J. Webb and W. Watson Buchanan

synthesis and pharmacological evaluation of amide derivatives of non-steroidal anti-inflammatory drugs

M.-F. Otis, L. Levesque, F. Marceau, J. Lacroix and R.C.-Gaudreault 
Table 1 continued

Vol. 1 no. 3; 1992 Contents

Partial liver resection and inflammation: role of exogenous glucocorticoids

R. Coimbra, P. Sannomiya, S. Rasslan and J. Garcia-Leme

Evaluation of the inflammatory activity in rheumatoid arthritis. Nanocolloid scintigraphy vs. clinical examination and bone scintigraphy

A. von Heijne, P. Seideman and M. Dahlborn

Double-blind randomized controlled trial and six-year open follow-up of yttrium-90 radiosynovectomy versus triamcinolone hexacetonide in persistent rheumatoid knee synovitis

E.N. Grant, N. Bellamy, K. Fryday-Field, T. Disney, A. Driedger and K. Hobby

Report on the Third International Symposium on Gastrointestinal

Cytoprotection, Pecs, Hungary, October 7-8th, 1991

K.D. Rainsford

Reduction of bleomycin-induced sequestration of neutrophils and vascular injury in hamster lungs by nitroglycerin

Q. Wang, D.R. Haynam, D.M. Hyde, A.B. Combs and S.N. Giri

Effects of human recombinant IL-1 $\beta$ on established experimental arthritis in rats

E. Drelon, P. Gillet, J.Y. Jouzeau, P. Fener, A. Bousseau, G. Charrière,

B. Terlain and P. Netter

Announcement

Vol. 1 no. 4; 1991 Contents

Letters to the Editor

Paradoxical effect of dexamethasone administration to rabbits with

antigen-induced arthritis

A.J. de Brum-Fernandes, V. de Falco, F.A. Castro da rocha and S. Jancar

Distribution of gold in human platelets after in vitro interaction and during chrysotherapy with gold sodium thoimalate

Y.B. Kassam, W.F. Kean, C.J.L. Lock, G.T. Simon and W.W. Buchanan

Conditional pharmacology: II. Ambivilant effects of aurocyanide, a putative active metabolite of anti-arthritic gold drugs, on human and rat PMN leucocytes

S.J. Gadd, M.W. Whitehouse and B. Vernon-Roberts

The effect of slow acting antirheumatic drugs on the production of cytokines by human monocytes

V.A. Danis, D.A. Rathjen and P.M. Brooks

Idiopathic chronic facial pain: tricyclic antidepressant drug action is not due to free radical scavenging (antioxidant) activity

M. Wasil, B. Henderson and M. Harris

Human neutrophils stimulated by cetyltrimethyl ammonium bromide generate luminol-amplified and non-amplified chemiluminsecence but no superoxide production: a paradox

I. Ginsburg, R. Misgav, A. Samuni, D.F. Gibbs, J. Varani and R. Kohen

Elevation of intestinal substance $\mathrm{P}$ by acute acetic acid in rabbits:

Modification by infant formulas

M.J.S. Miller, M.E. Becerra, M. Wong, X.-J. Zhang, H. Sadowska-Krowicka,

D.J. Albrecht, D.A. Clark and A.Y. Jeng

Short communication

Observations on measurement of 2,3- and 2,5-dihydroxybenzoic acid using high performance liquid chromatography

B. Aghabeigi and B. Henderson

Meeting Report

First International Congress of the Worldwide Hungarian Medical Academy

K.D. Rainsford 
Table 2 Inflammopharmacology conference series (with side-effects of anti-inflammatory drugs symposia)

Conference details and publications of proceedings

2.

3.

4.

5.

6.

7.

8.

9.

10.
Side-Effects of Anti-Inflammatory/Analgesic Drugs

(K. D. Rainsford and G. P. Velo, Organisers)

Venue: University of Verona (Italy), September 1982

Publication, Book: Side-Effects of Anti-Inflammatory/Analgesic Drugs. Advances in inflammation research, 6

Editors: K. D. Rainsford and G. P. Velo. Raven Press, New York, 1984

Side-Effects of Anti-Inflammatory Drugs

(K. D. Rainsford and G. P. Velo, Organisers)

Venue: University of Cambridge \& Queens' College, Cambridge (UK) 31st July to 2nd August, 1985

Publication, Book: Side-Effects of Anti-Inflammatory Drugs, 2 Part Volumes

Editors: K. D. Rainsford and G P Velo. MTP Press, Lancaster, 1985

Side-Effects of Anti-Inflammatory Drugs

(K. D. Rainsford and G P Velo, Organisers)

Venue: University of Verona (Italy), 8th-11th May, 1991

Publication, Book: Side-Effects of Anti-Inflammatory Drugs, 3

Editors: K. D. Rainsford and G. P. Velo. Kluwer Academic Publishers, Lancaster, 1992

Side-Effects of Anti-Inflammatory Drugs

(K. D. Rainsford, Organiser)

Venue: Sheffield Hallam University, 7-9th August, 1995

Publication, Book: Side-Effects of Anti-Inflammatory Drugs, IV

Editors: K. D. Rainsford and G. P. Velo. Kluwer Academic Publishers, Dordrecht, 1997

Publication (peer-review papers): Inflammopharmacology, Vol. 3, pp 137-204 and 311-399, 1996

Side-Effects of Anti-Inflammatory Drugs

(K. D. Rainsford and M C Powanda, Organisers)

Venue: South San Francisco Conference Center, 17th-19th March, 1997

Publication, Book: Safety and Efficacy of Non-Prescription (OTC) Analgesics and NSAIDs,

Editors: K. D. Rainsford and M. C. Powanda, Kluwer Academic Publishers, Dordrecht, 1998.

International Conference on Inflammopharmacology and 6th Symposium on Side Effects of antiinflammatory Drugs

Venue: Chateau Elan, Braselton. Georgia, USA, 23rd-26th may, 1999

Publication: Inflammopharmacology, Vol. 7, pp 191-303, 339-350

International Conference on Inflammopharmacology and 7th Symposium on Side Effects of antiinflammatory Drugs

Venue: Sheffield Hallam University, Sheffield, 10th-13th September, 2001

Publication: Inflammopharmacology, Vol. 9, pp 101-216

International Conference on Inflammopharmacology and 8th Symposium on Side Effects of antiinflammatory Drugs

Venue: Royal College of Physicians of Edinburgh, Edinburgh, 22nd-24th April, 2003.

Publication: Inflammopharmacology, Vol. 11, pp 301-470

Nineth International Conference on Inflammopharmacology

Venue: Queens' College, University of Cambridge, Cambridge, 8th-10th September, 2008

Publication: Inflammopharmacology, Vol. 16, pp 286-324

10th International Conference on Inflammopharmacology: 20 Years of Inflammopharmacology

Venue: Department of Pharmacology. University of Cambridge, Cambridge, UK. 4th-6th July 2011 
perhaps I should ask Dr. Klüber if he would be interested in publishing Inflammopharmacology. It emerged during discussions that he was looking for complementary publications to fit with the Birkhäuser portfolio of journals that included Inflammation Research (formerly Agents and Actions) with whom I had previously had editorial involvement. It seemed that the focus of Inflammopharmacology on pharmacological aspects of the therapy of inflammatory diseases, would be a neat complement to the understanding of inflammatory processes which was the focus of Inflammation Research. With my past involvement in the latter journal we had the basis for developing complementary publications and through personal contacts via the editors we could see a basis for establishing a working plan for both journals working independently of one another.

After Inflammopharmacology moved to Birkhäuser, the scientific and medical journals from this publisher were taken over and incorporated into the portfolios of Springer Basel AG, a subsidiary of Springer AG (Heidelberg). This was a fortuitous development since we now had the support of the extensive publication systems and expertise of Springer. I would also mention that it was the enthusiasm, expertise and invaluable support of Dr. Klüber that enabled

Table 3 Most frequent citations and frequently accessed articles in Inflammopharmacology

A. Most highly cited articles in inflammopharmacology

Skaper SD, Facci L, Fusco M, Della Valle MF, Zusso M, Costa B, Giusti P (2014) Palmitoylethanolamide, a naturally occurring diseasemodifying agent in neuropathic pain. Inflammopharmacology 22(2):79-94

Goyal N, Rana A, Ahlawat A, Bijjem KR, Kumar P (2014) Animal models of inflammatory bowel disease: a review. Inflammopharmacology 22(4):219-33

Cock IE, van Vuuren SF (2014) Anti-Proteus activity of some South African medicinal plants: their potential for the prevention of rheumatoid arthritis. Inflammopharmacology 22(1):23-36

Ellulu MS, Khaza'ai H, Abed Y, Rahmat A, Ismail P, Ranneh Y (2015) Role of fish oil in human health and possible mechanism to reduce the inflammation. Inflammopharmacology 23(2-3):79-89

Bartels LE, Bendix M, Hvas CL, Jørgensen SP, Agnholt J, Agger R, Dahlerup JF (2014) Oral vitamin D3 supplementation reduces monocytederived dendritic cell maturation and cytokine production in Crohn's disease patients. Inflammopharmacology 22(2):95-103

Afzal M, Safer AM, Menon M. (2015) Green tea polyphenols and their potential role in health and disease. Inflammopharmacology 23(4):151-61

Khan N, Smith MT (2014) Multiple sclerosis-induced neuropathic pain: pharmacological management and pathophysiological insights from rodent EAE models. Inflammopharmacology 22(1):1-22

El-Agamy DS, Makled MN, Gamil NM (2014) Protective effects of agmatine against D-galactosamine and lipopolysaccharide-induced fulminant hepatic failure in mice. Inflammopharmacology 22(3):187-94

Slomiany BL, Slomiany A. (2014) Role of ghrelin-induced phosphatidylinositol 3-kinase activation in modulation of gastric mucosal inflammatory responses to Helicobacter pylori. Inflammopharmacology 22(3):169-77

Vitetta L, Linnane AW (2014) Endocellular regulation by free radicals and hydrogen peroxide: key determinants of the inflammatory response. Inflammopharmacology. 22(2):69-72

B. Top 10 downloaded articles in inflammopharmacology

Graham GG, Davies MJ, Day RO, Mohamudally A, Scott KF (2013) The modern pharmacology of paracetamol: therapeutic actions, mechanism of action, metabolism, toxicity and recent pharmacological findings. Inflammopharmacology 21(3):201-32

Rainsford KD (2009) Ibuprofen: pharmacology, efficacy and safety. Inflammopharmacology 17(6):275-342

Vitetta L, Bambling M, Alford H (2014) The gastrointestinal tract microbiome, probiotics, and mood. Inflammopharmacology 22(6):333-9

Goyal N, Rana A, Ahlawat A, Bijjem KR, Kumar P (2014) Animal models of inflammatory bowel disease: a review. Inflammopharmacology 22(4):219-33

Ellulu MS, Khaza'ai H, Abed Y, Rahmat A, Ismail P, Ranneh Y (2015) Role of fish oil in human health and possible mechanism to reduce the inflammation. Inflammopharmacology 23(2-3):79-89

Chan YS, Cheng LN, Wu JH, Chan E, Kwan YW, Lee SM, Leung GP, Yu PH, Chan SW (2011) A review of the pharmacological effects of Arctium lappa (burdock). Inflammopharmacology 19(5):245-54

Maes M, Fišar Z, Medina M, Scapagnini G, Nowak G, Berk M. (2012) New drug targets in depression: inflammatory, cell-mediated immune, oxidative and nitrosative stress, mitochondrial, antioxidant, and neuroprogressive pathways. And new drug candidates-Nrf2 activators and GSK-3 inhibitors. Inflammopharmacology 20(3):127-50

Thomas S, Baumgart DC (2012) Targeting leukocyte migration and adhesion in Crohn's disease and ulcerative colitis. Inflammopharmacology 20(1):1-18

Jinesh S (2015) Pharmaceutical aspects of anti-inflammatory TNF-blocking drugs. Inflammopharmacology 23(2-3):71-7

Khan MA (1999) Chemical composition and medicinal properties of Nigella sativa Linn. Inflammopharmacology. 1999 7(1):15-35. [See also recent update: Akram Khan M, Afzal M (2016) Chemical composition of Nigella sativa Linn: Part 2 Recent advances. Inflammopharmacology 24(2-3):67-79] 
then and now to vastly improve the presentation and distribution of the journal worldwide. To me personally, Dr. Klüber has been of immense help and support in the whole process of publishing the journal.

The quality and interest in the journal has now reached the stage of it being recognized as a leading journal in the field of basic and clinical research focussing on the actions of existing and novel therapies for treating the wide range of acute and chronic painful inflammatory diseases. This is reflected in the frequent citations and assessing of articles (downloads) (Table 3). From time to time we adjusted the focus or topics that are covered in the journal in keeping with changes in the fields of therapeutics of acute and chronic inflammatory conditions. We hope that this journal can continue its mission in meeting future challenges for advancing and developing new and safer drugs for the large number of diseases that are encompassed by "acute and chronic inflammatory conditions".

The success of the journal would not have been possible without the active support and encouragement of the specialist Editors and members of the Editorial Board. Inflammopharmacology has always been an independent organ without commercial support or commercial advertising (aside from books or journals from Springer, which has no financial involvement in the journal). The Editors and Reviewers who receive no recompense are to be thanked for their invaluable help and immense support in ensuring selection and scrutiny of submitted papers that are of high quality and interest to the wide readership of the journal. We regularly monitor the standard of papers and a measure of the value of the outputs of the journal can be shown in the numbers of downloads and citations through various electronic sources (PubMed, Web of Science, Google Scholar, SciMago, etc.). There have been over 30,000 downloads of the journal articles from Springerlink annually. PubMed and Google Scholar give the journal a wide coverage. The most recent Thompsons Reuter's Impact Factor for 2015 of 2.304 is recognition that Inflammopharmacology is widely cited and has impact comparable with other leading journals in cognate fields.

We propose to expand the scope of the journal to embrace (1) advances in the safe and effective therapy with opioids, cannabinoids and other agents that affect neuroinflammatory and neuro-degenerative diseases; (2) the discovery of compounds from natural products and chemically designed compounds developed to act on newly discovered inflammatory or pain-producing targets; (3) modification of existing drugs or agents to enhance their efficacy and reduce frequently occurring adverse or sideeffects via pharmacokinetic and/or pharmacodynamic modifications; (4) critical review and clinical evaluation of current drugs used to treat painful inflammatory diseases, especially using advanced statistical procedures (e.g. algorithms designed to be adapted to small patient numbers or intrinsically complex conditions (back pain, neuropathologic states), and (5) the accurate application of nonselective meta- and group-analyses, and assessments of impartial judgements of clinical data-these procedures being employed to enable unbiased critical recognition of those conditions that positively or negatively affect the efficacy and safety of drugs or that may give lead for adapting or modifying existing or novel drugs as advanced therapeutics.

The journal will always be an open forum for critical exploration of new ideas and objective re-evaluation of older or established ideas and concepts.

We look forward following the first 25 years to an exciting future from which it is hoped to discover new approaches regulate the vast array of inflammatory processes that underlie many diseases. 